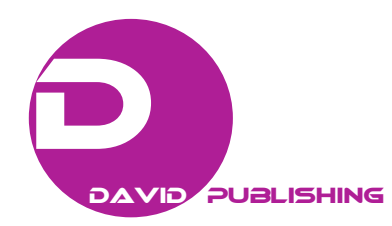

\title{
Research on the Spatial Form of Folk Academy in Xiangxi Area-Taking Chongshi Academy as an Example
}

\author{
Ying Wang and Xiaofeng $\mathrm{Li}$ \\ Architecture and Urban Planning School, Huazhong University of Science and Technology, Wuhan 430074, China
}

\begin{abstract}
In the development process of the entire academy of Xiangxi (China), there are lots of difficulties but it has a unique charm. Both the architectural culture and the college culture collide with the regional culture, creating a spark of difference. This paper, taking Chongshi academy as an example, elaborated and analyzed cases from four aspects of historical evolution, architectural layout and site selection environment, architectural space composition and elements, and architectural decoration art for in-depth investigation of the case, and carried out field research mapping to provide a reliable basis for relevant research.
\end{abstract}

Key words: Chinese folk academy, spatial form, Chongshi Academy, architectural culture.

\section{Introduction}

The education of the academy plays an important role in the long history of traditional Chinese education. Its architectural layout and spatial organization are different from those of official academies. It is an educational building with its own characteristics. The Chinese academy has a traditional Chinese culture, and the impact is broad and profound. The folk academies are deeply rooted in the country throughout the whole nation, and their education is oriented to the grassroots of the society and has made great contributions to the popularization of cultural education.

The historical process of the founding, prosperity and decline of Xiangxi Folk Academy is different from that of folk academies in other regions. Due to the influence of regional politics and other aspects, the Xiangxi Folk Academy has developed rapidly after the reform of the Qing Dynasty. Due to the influence of regions, ethnic groups and different cultures, the Xiangxi Folk Academy has different characteristics

Corresponding author: Ying Wang, doctoral candidate, research fields: architectural design and theory. from other traditional college buildings. Chongshi Academy is an important material of Xiangxi Academy's architectural evolution and the architectural pattern of Xiangxi academy [1]. The academy is well preserved and is a provincial-level cultural relics protection unit at present. This article took Chongshi Academy as a typical case to explore its spatial form.

\section{Chongshi Academy Overview}

Chongshi Academy located in Yanban Village, Longtan Town, Xupu County, with three courtyards, has a complete structure and a large scale. The Chongshi Academy is an important part of the development of Xiangxi Academy and the architectural structure of Xiangxi Academy (shown as Fig. 1). Huaihua Academy has a long history of education. According to the "Huaihua District Records", since the Qing Dynasty, Huaihua has established 55 more famous academies. This large number of outstanding academies has trained a large number of ethnic writers and artists, and their contributions to the cultural and educational undertakings in Xiangxi cannot be underestimated. 


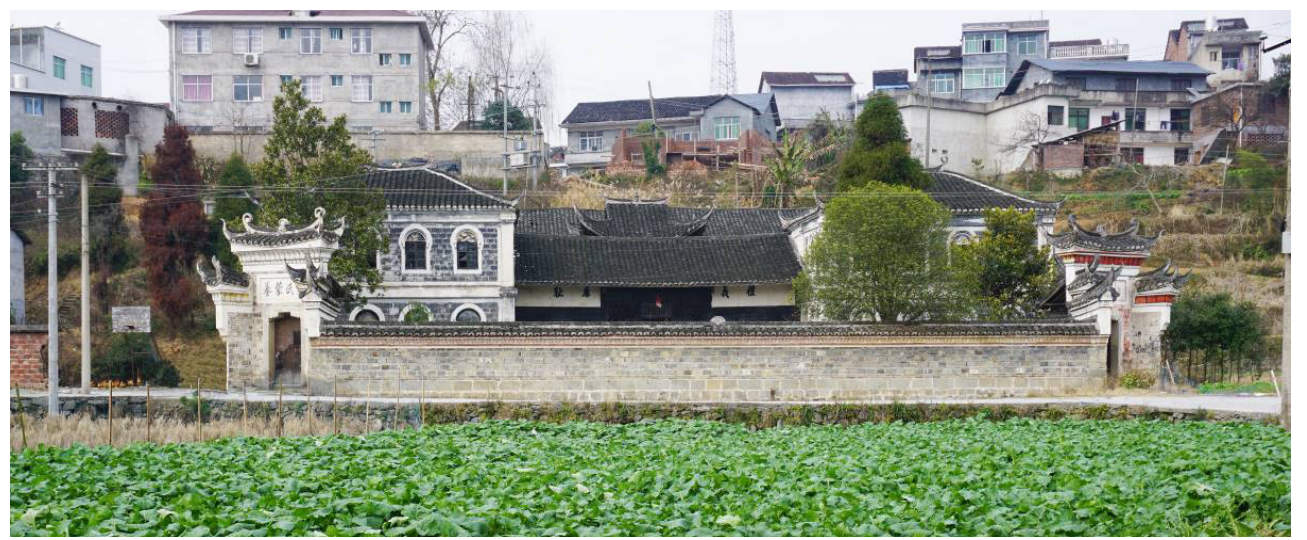

Fig. 1 Front elevation of Chongshi Academy.

It is located in the Yanban Village, Longtan Town, Zhangpu County, and is a typical family academy. It was built in the 14th year of Qing Daoguang (1834) and was donated by the Wu's people. It was a two courtyards style building at the time of its construction. It was originally called the Yanling Family School. A horizontal inscribed board named "Wu's Kindergarten" of the brick on the door was judged to be founded by Wu's people. It changed name of Chongshi Academy in Xianfeng five years (1855). The academy was originally a two-in-one courtyard [2]. It was converted from an ancestral hall to an academy, so its layout was in the form of an ancestral hall, with a lobby. In the thirty-second year of Guangxu (1906), it was renamed as "Chongshi Academy" and took the meaning of rejecting luxury and upholding simplicity. The academy was expanded to the existing three courtyards until 1921 and it has been well preserved up to now.

The center position of the village entrance or the family is preferred as the first place to facilitate the arrival of the children. Going straight forward from the college more than 50 meters, it is Xu Water. The land is flat and is a Feng Shui treasure. Feng Yu Bridge serves as a cross-strait connection (shown as Figs. 2 and 3). It was also built by the Wu family. The Feng Yu Bridge is simple and elegant. People can sit on the Feng Yu Bridge quietly. The academy sits in the northwest and faces the southeast. It is a three courtyards layout. It is backed by mountains and waters. It is open on three sides. The Xu Water is very close to the academy. It is backed by mountains and has a wide view in front of the courtyard.

\section{The Function and Layout of Chongshi Academy Building}

Chongshi Academy is the largest case of the existing folk academy in western Hunan. It covers an area of 2,473 square meters and has a construction area of 1,553 square meters [3]. It is a courtyard of the three-in-one hall, a mixed structure of brick and wood, and its roof is a hanging mountain roof form. The architectural form of the Chongshi Academy is built by the traditional form of the Chinese academy. The layout of the building is regular and symmetrical. The front floor of the house is wide and builds a brick enclosure. The wall of the academy and the fence are connected together. The bottom of the fence is made of granite, and the upper floor is made of blue brick. One of the most noteworthy is that half of the moon-shaped pond in front of the wall of the college is Pan Pond, surrounded by Huanggang rock, which is obviously influenced by the official academy. The southeast and southwest corners of the wall open a main entrance. The courtyard door is a figure-eight brick structure with complex shapes. The east side door has "Chongshi Academy" and the west side door has "Wu's kindergarten".

The overall layout of the academy is rigorous and the axis is symmetrical. It consists of the gate, the 


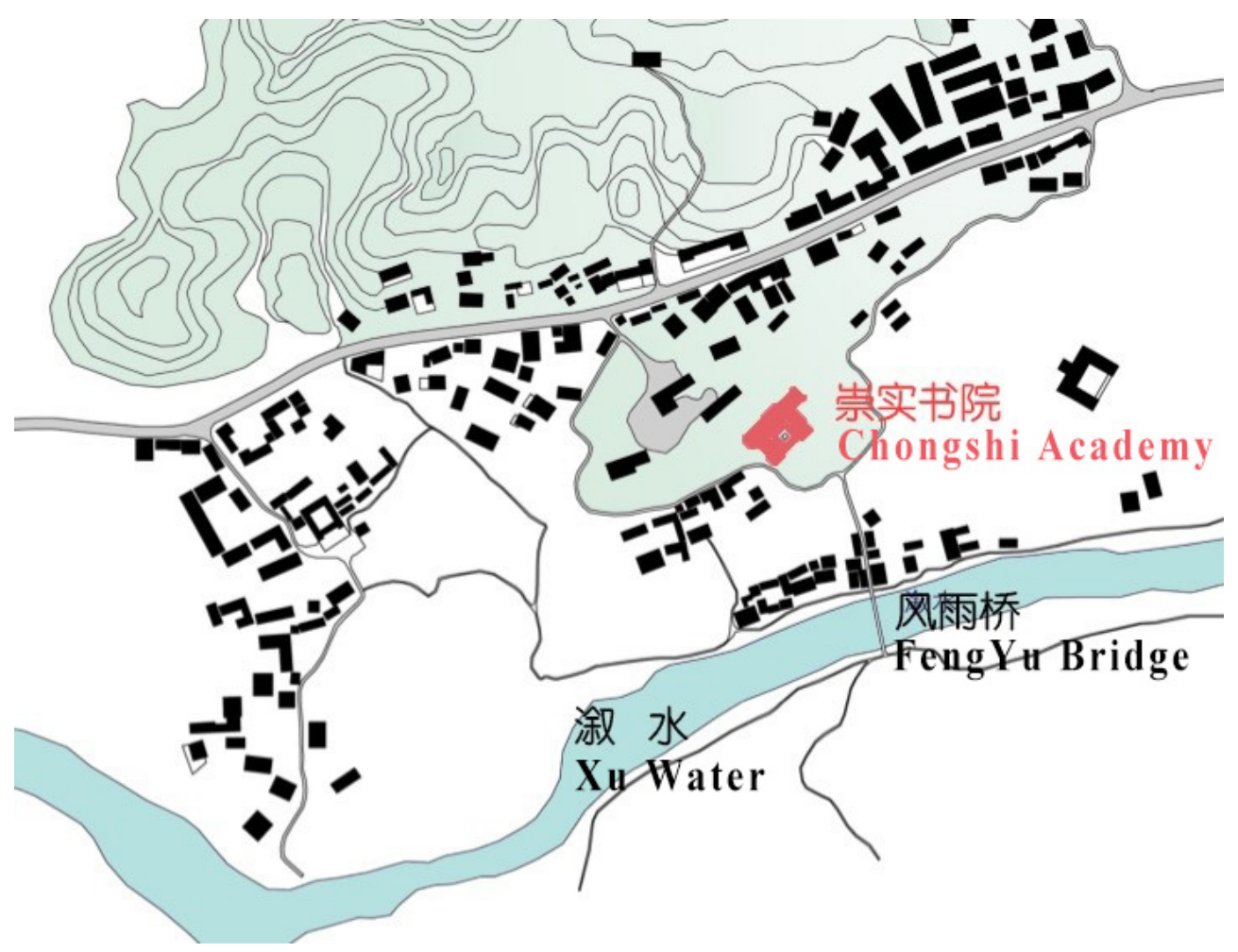

Fig. 2 The location of Chongshi Academy.

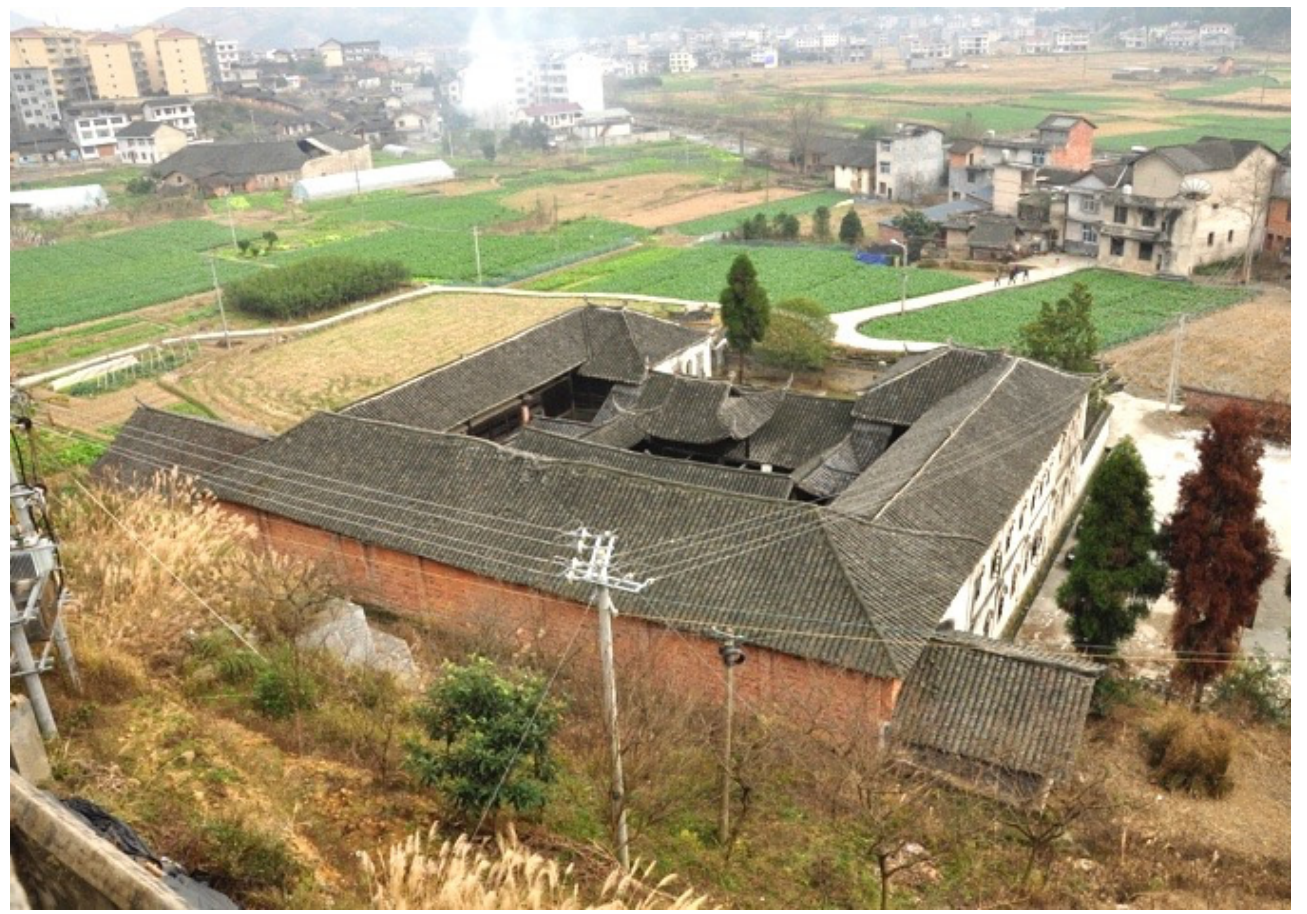

Fig. 3 The environment of Chongshi Academy.

lecture hall, the ceremonial hall and the left and right shacks (two layers). It conforms to the layout concept of "the lecturer has a hall. The tour has a place to play and rest. Study room is a living room, and the house is not available" (As shown in Fig. 4). Two rooms are symmetrically arranged on both sides of the main 


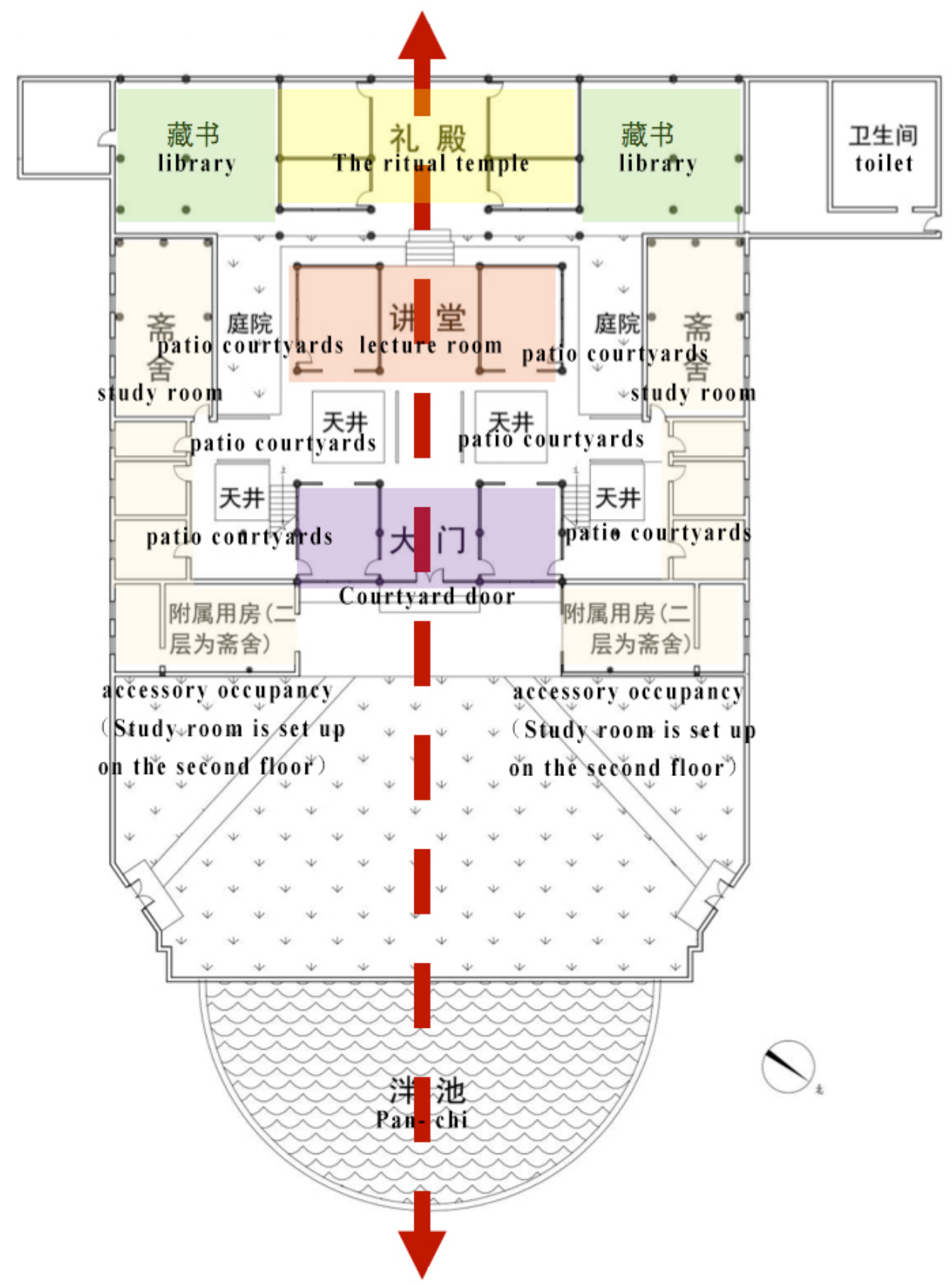

Fig. 4 Chongshi Academy's graphic function layout.

entrance. The left side is the kitchen, the right side is the storage room, and the lecture hall is hanged a plaque bamboo filament (Fig. 5) named "The Foundation of Scholarship" in the first year of Qing Xuantong (1909). There are two small lecture halls on both sides of the lecture hall. The small lecture hall is 0.3 meters high on the ground. The wooden keel is laid on the lower slab. There is a four-corner pavilion clock tower between the gate and the lecture hall, whose height is 9 meters and the roof is like the top of the mountain (shown as Fig. 6). The academy was originally provided with a statue of Confucius and worshipped the sages. Although the height of the building on the central axis of the academy is generally lower than the height of the two-storey house on the two sides, the distinctive clock tower is 


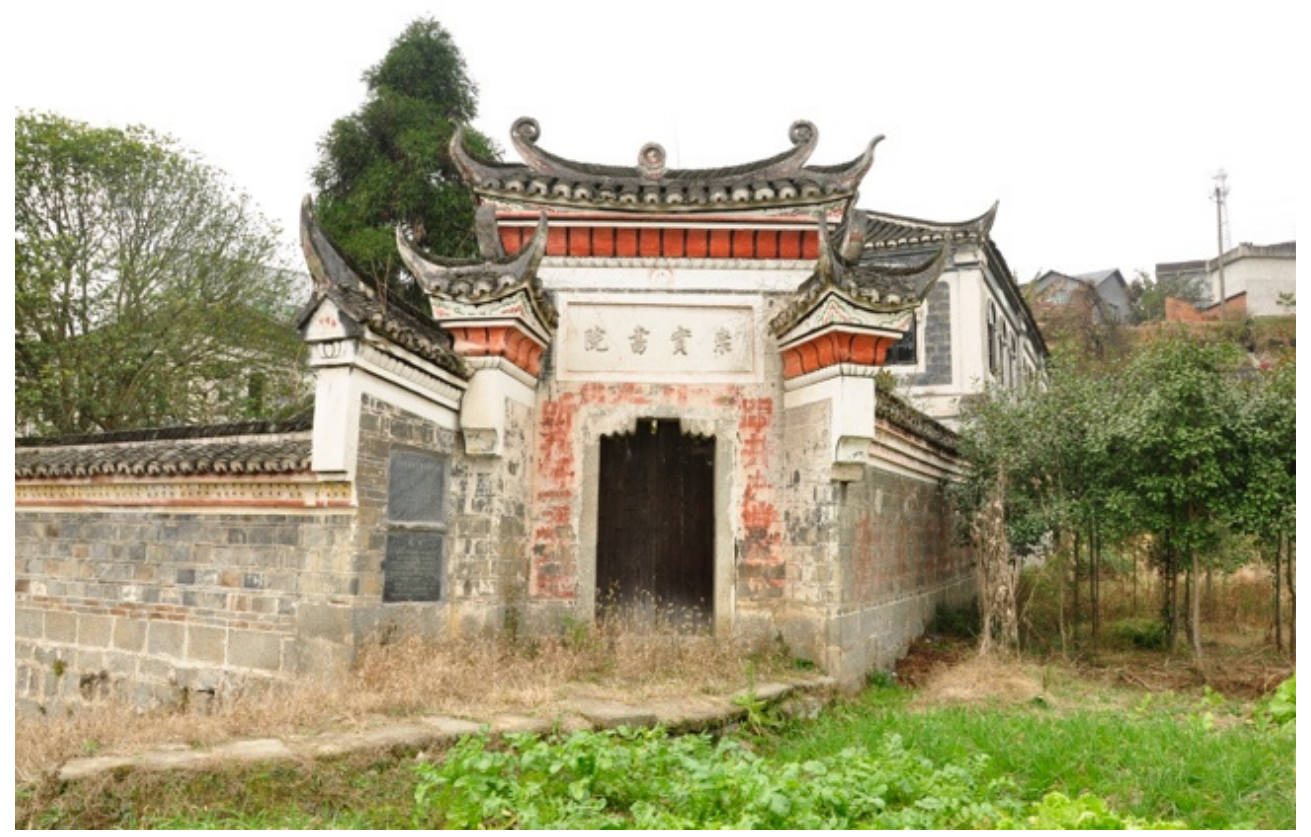

Fig. 5 East gate of Chongshi Academy.

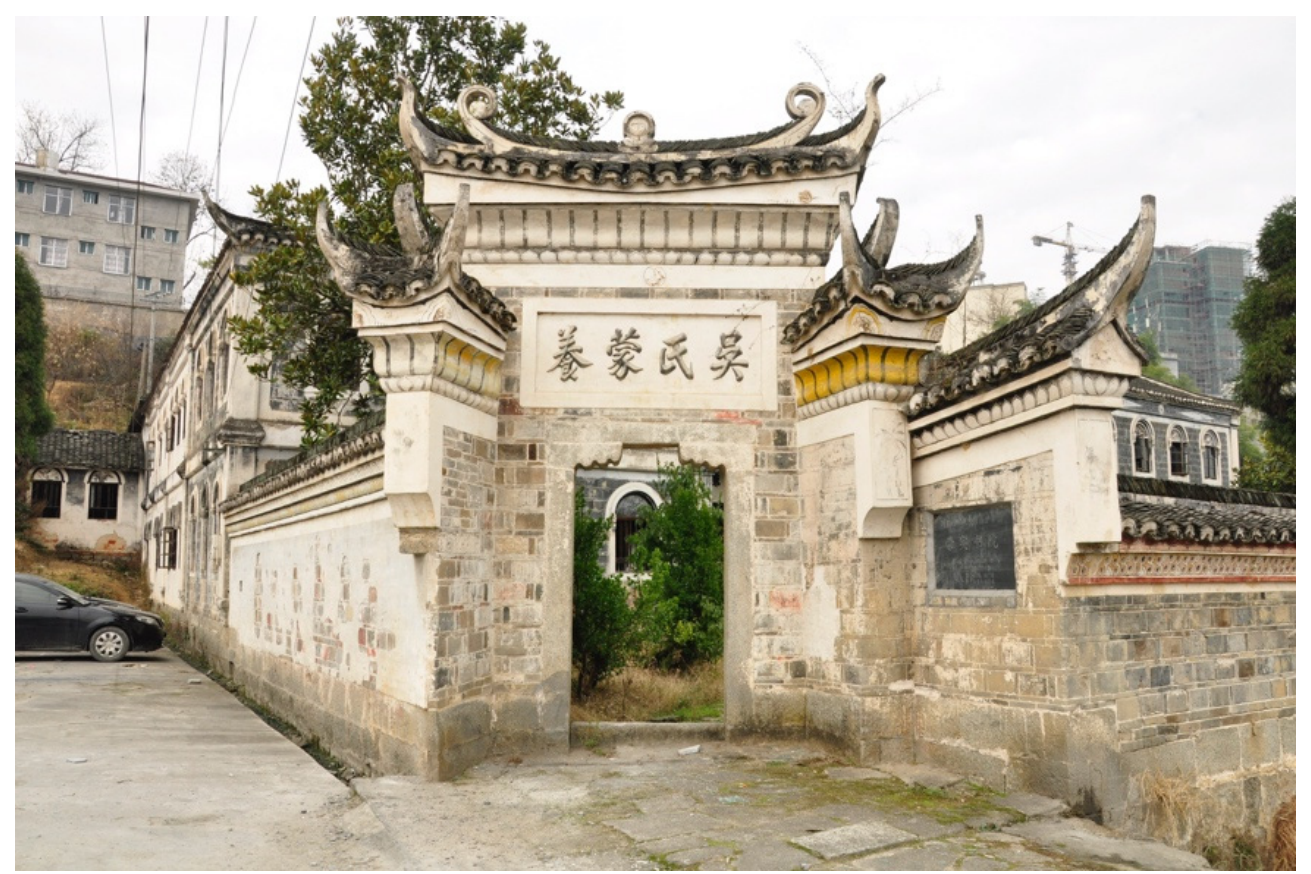

Fig. 6 West gate of Chongshi Academy.

directly in the lecture hall and the gate, and the height is more than two floors, leading the overall situation in space height.

The four-cornered wooden bell tower between the main entrance and the lecture hall also implies that the central structure and central area of the academy is completely symmetrical, also reminds the importance of the central axis of the building. There are six small and exquisite patio courtyards in the overall layout of the academy, arranged in a symmetrical layout, enriching the architectural space form and increasing the sense of space.

From the overall perspective, the architectural style is simple and generous, harmonious and unified, and 
the detailed treatment reflects the exquisiteness of the Xiangxi dwellings. The architectural image is rich and dexterous, clear and bright. The overall layout of the Chongshi Academy is rigorous. What is commendable is that it is a privately-owned folk academy. It not only worships Confucius but also repairs a Pan-chi in front of the academy. Such a form is extremely rare among other folk academies in Hunan.

\section{The Building Space Composition and Elements of Chongshi Academy}

The statistics of architectural space composition and elements of Chongshi Academy are shown in Table 1.
The gate of the Chongshi Academy is three-opened with a bucket-type wooden structure. It is one layer with 12 meters wide and 4.5 meters deep. The eaves are wide and the middle is the hall. The two sides of the room are for teachers. The doors and windows of the building are traditional carved openwork windows, simple and natural.

The lecture hall is a three-open room, with column and tie wooden construction. It has one layer with a width of 12 meters and a depth of 4.8 meters [4]. The middle is a lecture hall. The wing rooms on both sides are small lecture halls. The small lecture hall is 0.3 meters high on the ground, and the wooden keel on the lower floor is covered with wooden boards. The

Table 1 Chongshi Academy single building statistics.

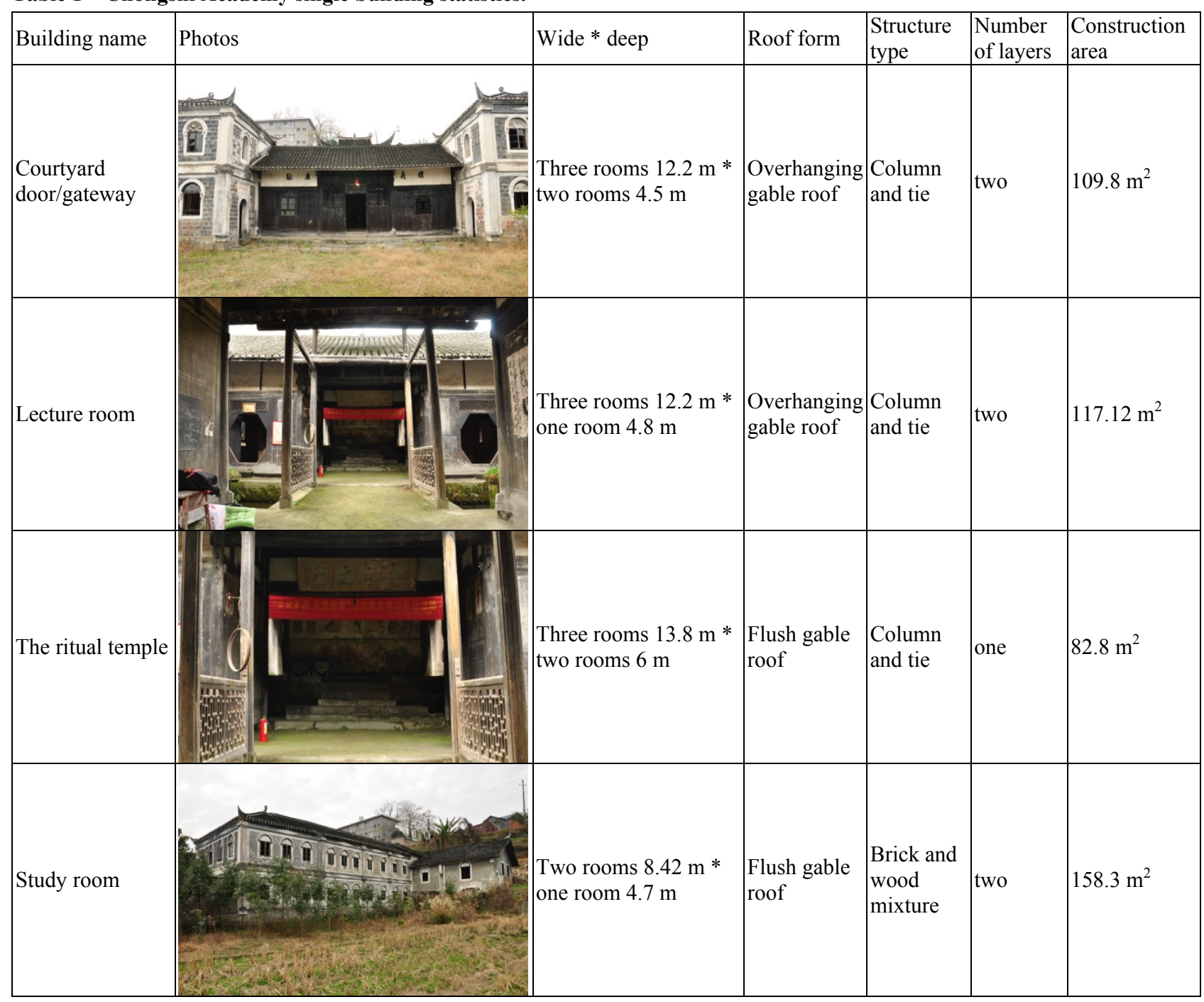


rules and regulations, donations, celebrations, etc. of the Chongshi Academy are hung on the wall.

The temple is located at the highest point of the academy. It is used to worship Confucius, also known as Dacheng Hall. It is 1.5 meters above the floor of the lecture hall. It has a width of 12 meters, a depth of 6 meters and a height of two floors. Now the second floor has been destroyed. The side is the wing room. Then, toilets were built on the east and west sides of the academy hall.

The two sides of the lecture hall are two-storey high. Now it is used as a classroom. The inner courtyard is combined with the central axis. The wall facing the courtyard is a wooden partition wall. The partitions are made of hollowed doors and windows. The carvings are exquisite and can be used for ventilation and lighting, but also can play the role of beautiful decoration. The exterior wall is blue brick, durable and fireproof. The façade is decorated with western-style window holes, decorated with white lines. On the wooden stairs, going to the second floor of the house, the floor is made of wooden slabs, separated into two large rooms and a small room. The large room is a classroom with wide space and the lighting is good. The small room is the teacher's living room, and there is still a discarded wooden bed.

The courtyard is between the entrance of the academy and the wall is large and spacious. There are six stone tablets embedded in the wall, which records the school history, purpose, funding, scholarship system and accomplished students of the Chongshi Academy. In the courtyard, these ancient cherry bays are embraced. The pomegranate burst into gorgeous bloom. The green covered the sky, and the environment here is quiet.

There are six small and exquisite patio courtyards in the academy (As shown in Fig. 7), which are arranged symmetrically on both sides of the central axis, and are connected between the individual units and the courtyard through the corridors to form a complete traffic corridor. Even in the rainy season, shoes can be used without water, and it is convenient to walk and more convenient for teaching and activities. The opposites of the monolithic buildings are closely related, but the functional zones are connected through the corridors, and the courtyards of different sizes are combined through the corridors and the buildings. The scattered individual monomers are connected with each other, and more small patios are formed at the same time, which is suitable for the climate characteristics of the western Hunan region, and communicates with the sunlight through the patio, enriching the entire building group space and increasing the spatial hierarchy in the space. In terms of spatial arrangement, the courtyard weakens the regularity of architectural layout, making the architectural space flexible and changeable.
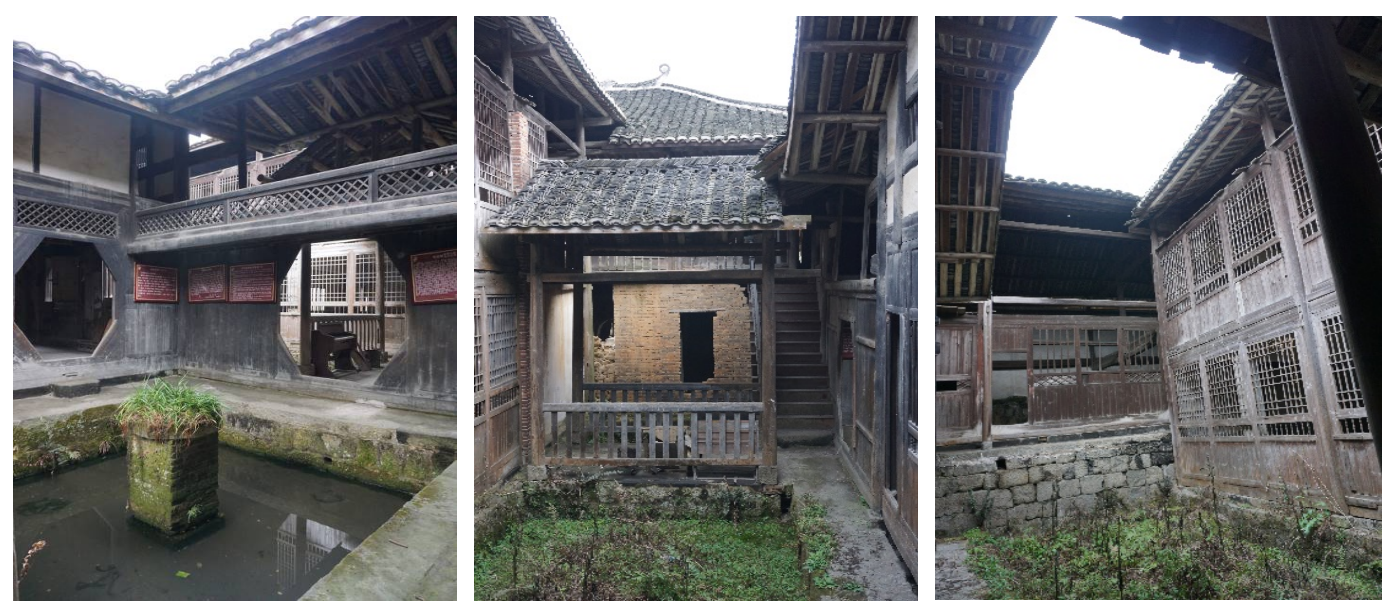

Fig. 7 Patio courtyards of Chongshi Academy. 


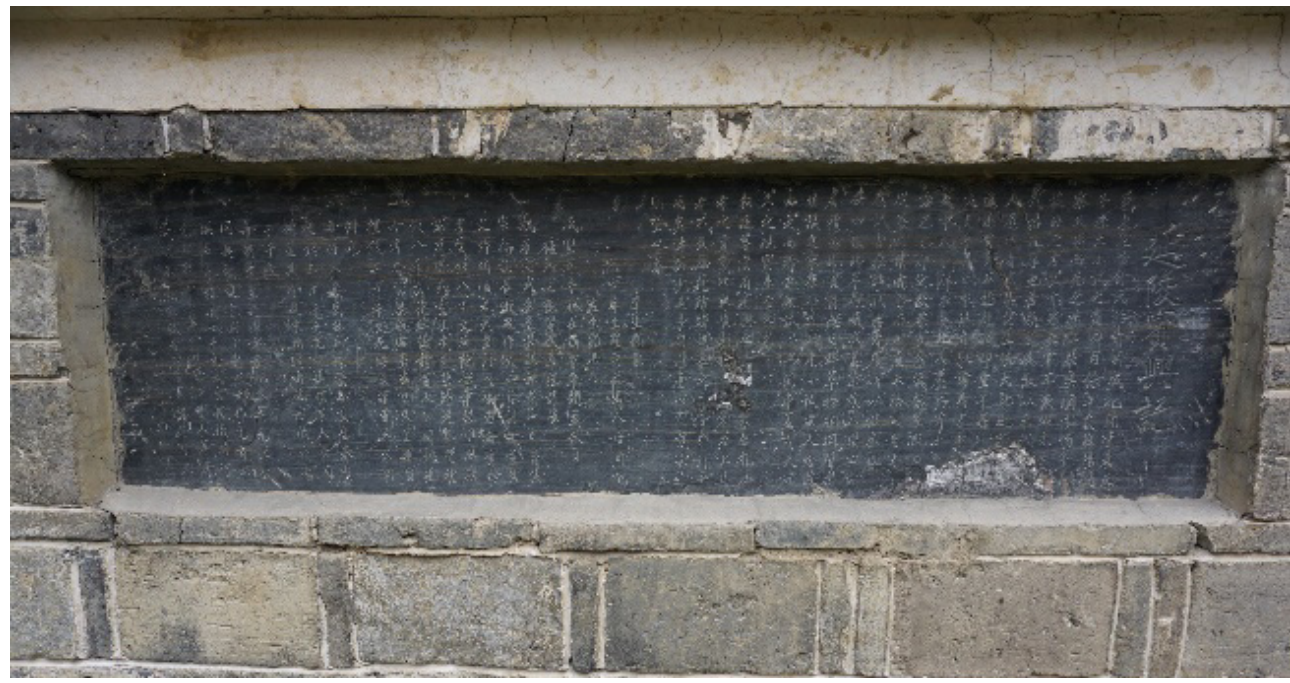

Fig. 8 "Yanling shixing tablet preface" of inscription on the screen wall.

\section{The Building Decoration Art of Chongshi Academy}

There are not many decorative arts in Chongshi Academy, but in the detail. There are many stone inscriptions on the inner wall of the courtyard (as shown in Fig. 8). The green brick wall is everlasting, and the inscriptions embedded in it tell the story of the academy. A screen wall facing the gate of a house has two doors with the east and west sides, called splayed door. Its unique shape is like a gate building. It has a charm and a national style.

The Wu family's family records the family history and the origins of the $\mathrm{Wu}$ family's private school. The $\mathrm{Wu}$ family moved from Jiangxi to Longtan Town in Xupu. In order to inherit the family tradition of learning, the private school was established [5]. There are six patios of different sizes in the academy, which are connected by corridors and octagonal doors. The doors and windows in the courtyard are carved and hollowed out, which is also beneficial to lighting and ventilation. The traditional three-carving and two-plastic crafts used in traditional Chinese architecture are not used much in the Chongshi Academy. What's puzzling is that the western-style façade has clear water brick wall, and the western-style arched door and cave. It is decorated with curved white lines, which may be related to the later modernization of the system, forming a unified and sequenced rhythm aesthetic on the façade.

The façade of the study room is a combination of Chinese and western columns, windows, wooden windows and reliefs. The author observed a wall with four different themes, the official flower of the four gentlemen called "plum, orchid, bamboo, chrysanthemum". The roof is blue roofing tile on the top of the mountain. The wooden structure of the college is painted with black lacquer, and the roof is gray and blue roofing tile. The beam is not carved in the decoration, only the doors and windows are straight and horizontal, and some buildings have hollow-out plaque plates beneath eaves. The second layer of provocative slanting braces is exquisitely carved, and the pattern is cirrus style. The whole academy mainly uses black as the main color, which reflects the cultural concept that Confucian advocates natural beauty, low-key and unpretentious creation.

\section{Conclusions}

The regional culture of Xiangxi is different from other parts of Hunan and has unique geographical differences. In the development process of the entire academy of Xiangxi, there are lots of difficulties but it has a unique charm. Both the architectural culture and the college culture collide with the regional culture, creating a spark of difference. Taking the Chongshi 
Academy in Xiangxi as an example, this paper elaborated and analyzed cases from four aspects of historical evolution, architectural layout and site selection environment, architectural space composition and elements, and architectural decoration art for in-depth investigation of the case, and carried out field research mapping to provide a reliable basis for relevant research.

\section{References}

[1] Wang, Y., and Li, X. F. 2017. "Discussion of the Ritual and Space in Xiqin Guild Hall Theater Based on Trade
Gods Worship.” South Architecture 1 (Jan.): 63-9.

[2] Wang, Y., Li, X. F., and Gan, Y. L. 2016. "Study on the Green Design Strategies of Neo-Vernacular Architecture.” Procedia Engineering 169 (Dec.): 367-74.

[3] Zhu, H. M. 2015. "Academies and Culture along the Changjiang River Valley.” Journal of Hunan University (Social Science) 3: 3-9.

[4] Yang, Y. Q. 2017. "The Spatial Form and Cultural Expression of Folk Academies in the West of Hunan Province." Master thesis, Huazhong University of Science \& Technology.

[5] Meskill, J. 1982. Academies in Ming China: A Historical Essay. Tucson, Arizona: The University of Arizona Press. 